\title{
Words and Pictures: Back to basics for effective learning in the health sciences
}

\author{
Michelle Thunders, Ying Jin, Jim Clarke, Dan Wadsworth, Judy Thomas, Rachel Page \\ IFNHH, College of Health, Massey University, New Zealand \\ M.Thunders@massey.ac.nz
}

\begin{abstract}
Students often struggle with science content because of their lack of science vocabulary comprehension and the general bewilderment with facing lengthy segments of text without meaning. This paper reports on a two-pronged initiative to facilitate health science learning for first year degree students. Firstly, the introduction of visual diagrams into teaching practice. These diagrams summarize linkages between content and are valuable tools for visual learners and an important learning skill to develop for students new to the tertiary education environment. Secondly, development of an online science vocabulary tool. Science vocabulary is often derived from Greek and Latin words, languages not familiar to the majority of our students. Knowing common suffixes, prefixes and root words can facilitate student understanding of new complex concepts. Development of a visual, interactive and quick online tool to aid students dissect and decode parts of words and help them to understand the entire word. This is particularly beneficial for students otherwise disadvantaged, for example, students where English is not their first language and students with little or no previous science education as often the case for students undertaking the Bachelor Health Science (BHlthSci) degree. This could also help with first-year student retention as it may help students to not see science words as daunting and confusing and give them confidence in their learning. Preliminary survey results indicate a positive student response to the initiatives with the majority of students using these tools to focus their revision and incorporating them in their self-directed learning.
\end{abstract}

\section{Indexing terms/Keywords}

online tool, health science, vocabulary comprehension, moodle, visual learners, andragogy.

\section{Academic Discipline And Sub-Disciplines}

Education; health sciences

\section{Council for Innovative Research}

Peer Review Research Publishing System

\author{
Journal: INTERNATIONAL JOURNAL OF RESEARCH IN EDUCATION METHODOLOGY
}

Vol 5, No. 2

ijremeditor@gmail.com

www.ijrem.com 


\section{INTRODUCTION}

It is widely believed that good teaching is being able to get the majority of students to 'use the high cognitive level processes that the more academic students use spontaneously' (1). This in itself is not simple to achieve when faced with an increasingly diverse student population. The role of the lecturer is not simply to teach but also to foster an environment that supports good learning: being able to teach students how to learn, seek information, use and evaluate that information to solve problems. The way in which adults learn is largely affected by three major factors; personality, motivation and context. Major theories of adult learning focus largely on the learner and their needs from the learning process rather than on pedagogy. As such many theorists believe that 'andragogy', defined, as 'the art and science of helping adults to learn' (2), should be used to describe teaching adults rather than pedagogy. The founding principles to andragogy are that knowledge is actively constructed by the learner and that learning is an interactive process. The two initiatives described in this paper are very much focused on andragogy.

Rogers (3) described the learning process as 'learning means making changes' and as such emphasised the difference between teaching adults and teaching children. Adult learners have more choice in terms of their learning and have more life experience which could equate to being more resistant to change. How adults learn is also affected by personal noncognitive aspects such as level of education, training, health, and factors related to social /cultural context. There is a huge variation in learning styles and countless other contributing factors that make it difficult to develop one theory that encapsulates all adult learning. Lifelong learning is the 'need for all adults, whatever their previous level of educational attainment, to undertake the kind of education, training and self-development activities which will equip them to cope with the challenges of economic, social, demographic and technological changes' (4).

Higher education is becoming increasingly flexible to broaden its accessibility with a wider range of part-time degree courses, foundation courses, and correspondence courses, all of which have their benefits and failings. This makes higher education available to a wider group of people and as a consequence the demography of students in higher education has significantly changed over the last thirty years. The entrance of a broader student population also means that within one paper there now will be a much greater spread of student ability, motivation and life experience. This poses a significant challenge to a lecturer in terms of what level to pitch teaching particularly for large group teaching sessions. It is the case that our student population is becoming increasingly diverse in demographic and with this comes a more diverse base knowledge. A large and rapidly growing proportion of tertiary students in NZ are English language learners and simply lack English vocabulary to comprehend difficult texts. Manzo et al (5) report a decline in vocabulary levels of college bound 18year olds, there are also some students entering into our year one programme with little or no prior science background, or who are re-entering into study after a long period of time away from study. Therefore great differences exist between individual health science vocabulary levels of students taking a paper at any given time. Part of our role as educators is to try to level this disparity and facilitate learning strategies for those students with a more limited vocabulary.

Methods of teaching have also moved with technological progress and ICT becoming increasingly incorporated in teaching practice. The interactive learning environment (ILE) and packages such as Blackboard, Moodle and WebCT are amongst the widest used teaching evolution with the main benefits being increased flexibility. However, the main downfall of these approaches is the danger of isolation for those not IT literate. There is still a responsibility on the part of the educator to ensure students are equipped with the sufficient study skills to make meaning from an increasing body of available information. Literature suggests that if teaching is made more compatible with a students learning style then they may learn more, retain for longer and have a more positive attitude towards the subject. It is believed that approximately $40 \%$ of University students are visual learners (6). Visual diagrams that summarise linkages between content are valuable tools for visual learners. Visual summaries are multi-faceted tools that help students organize, integrate, and retain information. In addition to facilitate the organisation of information in the learning process, it is also vital that we address the issue of understanding complex scientific vocabulary. It has been suggested that one of the biggest barriers to learning science is learning the actual language of science itself (7). A lack of word knowledge disrupts fluency in reading and interferes with reading comprehension because word meanings can make up as much as $70-80 \%$ of comprehension (8). Health science, like all other sciences has a large specific vocabulary associated as well as a high density, compaction of information. For students not familiar with the jargon this can present information overload on their working memory and lead to feeling overwhelmed by the sheer density of information during text processing. Understanding word structure can be a powerful aid for students faced with learning a daunting health science vocabulary. A large number of these words could be comprehended if students knew some of the more common root words and be able to break the word down into component parts (9).

Effective word learners break down unfamiliar words into constituent meaningful parts, they then hypothesize their meanings and then check against the context of the text they are reading the word in. By doing this they are using their knowledge of high frequency root words to access low-frequency words. It has been well established that knowing a word means not just knowing its definition but also its relationship to other words, its' meanings in different contexts and how it can be transformed into different forms (10). The reader's knowledge and meaning of words and concepts are central to their success, with vocabulary linked to proficiency in reading comprehension. Many scientific terms have their derivative origins from Greek or Latin. Knowing the meaning of a number of core root derivatives can greatly aid comprehension and make learning in a health science subject more accessible.

In their paper on breaking down words to explore meaning, Kieffer and Lesaux (11) describe key principles for teaching morphology. This is the structure of words with morphemes being the smallest units of meaning. These principles include: 
- Teaching morphology in the context of rich explicit vocabulary instruction. This means repeated exposures to words and in meaningful contexts to stimulate an awareness of and interest in words and their meanings.

- Teaching students to use morphology as a cognitive strategy with explicit steps. So to recognize that a word is unknown, analyses word for morphemes, hypothesise the words meaning and then check against the context the word is given

- Teach underlying morphological knowledge needed both explicitly and in context. Knowledge of prefixes and suffixes, understanding of how words get transformed and knowledge of roots

Mountain (12) describes that morphemic analysis may be one way to narrow the gap between vocabulary 'haves and have not's'. Understanding the derivative root of a word can help immensely with the comprehension of a science word, i.e. knowing cardio relates to the heart, rhino relates to the nose. Kail (13) reports how teaching root words to students in an English class facilitated students comprehension in other areas, particularly the sciences. A key to successful vocabulary instruction is to get students engaged in interactive word-learning experience (14) and that which focuses their attention on learning clusters of words that share a common element/origin (15).

This paper reports on two 'initiatives' we have employed to facilitate the learning process for a large wide-ranging demographic cohort of first year undergraduate Bachelor of Heallth Science (BHlthSci) students. Firstly, the introduction of visual summaries as a teaching and learning tool to aid students in making sense of information-dense text. Secondly, to develop a highly visual, vocabulary tool to embed in the stream (Moodle) online learning environment to facilitate the recognition and learning of root words commonly found in two BHlthSci 100-level papers; 214.102, Applied Sciences for Health Professionals and 214101, Normal Body Function. The aim of this initiatve is to focus on the relationship between learning vocabulary and reading comprehension, with the understanding that growth in vocabulary knowledge and comprehension occurs more from seeing words in context rather than defining words in lists.

\section{PROCESS}

\section{Visual Summaries}

Visual Summaries developed had a central topic with main themes radiating as branches. Topics of lesser importance were represented by higher level branches with branches connected in a nodal structure and highlighted where cross linkages occur. One page visual summaries were incorporated into teaching sessions where the students were involved in generating the visual summaries, in large lectures, the lecturer used the student generation of visual summaries as a means of making the session a more active learning process. Typical lecture sizes are between 120 and 180 students. In a tutorial the visual summary was used to recap previous week's lectures at the start of a session. Students were strongly advised to develop these techniques for helping them make sense of the course material. To determine the students' perception of usefulness to their learning a short survey was distributed to students to address the question of whether the introduction of visual summaries improved student satisfaction. The survey comprised 6 yes/no questions (Did you use visual summaries in your revision?, Did the use of visual summaries help you answer test questions?, Are visual summaries a useful thing to include?, Did visual summaries help focus your learning?, Are visual summaries useful as part of a teaching session?, Are visual summaries useful in your self-directed learning?) and' a comments section.

\section{Science Vocabulary Tool}

In order to develop the vocabulary tool, the teaching team for both 214.101 and 214.102 first year health science papers initially developed a list of key scientific terms that are used in these first year health science papers. This list of words formed the basis of the initial tool developed. The initial tool was circulated around departmental teaching staff for input and feedback on additional roots and words to include. The tool was developed as a PowerPoint presentation comprising text and graphics imported from Clip Art and on continuous loop, initially at 6 seconds per slide with a pause function. This was integrated into the student's Moodle online learning environment for the paper as a 'pop-up' that the students could interact with. In addition the PowerPoint file was converted to a Flash Video (.FLV) format using the Xilisoft PowerPoint to Video Converter Free 1.1.1. The video was then embedded in the Moodle online learning environment for the Applied Sciences for Health Professional site. Further details on the development of this tool is reported in the proceedings from the Ascilite 2013 conference (16).

\section{OUTPUTS}

\section{Visual Summaries}

Initial feedback from teaching staff has been that the incorporation of visual summaries has benefited large group teaching where the development of visual summaries has been used as an 'in class' activity or as a revision aid. Figure 1 illustrates a visual summary generated in class to summarise the endocrine system. This has generally taken place as short 'time out' sessions where students brainstorm and work in pairs to come up with key concepts for a visual summary. Both staff and students have commented on the benefit of this opportunity for students to reflect and question their learning and thus enabled more active and effective learning in the large lecture setting. 49 students (41 percent of the enrolled cohort) completed the questionnaire. The response to the incorporation and use of visual summaries was very positive, $31 / 49$ used visual summaries in their revision, 40/49 thought use of visual summaries helped them answer test questions, 49/49 answered yes to visual summaries being a useful thing to include, 45/49 thought visual summaries helped focus their learning, 46/49 found visual summaries useful as part of a teaching session and 33/49 found visual summaries useful in their self-directed learning. Common themes raised by students in the survey were that the visual summaries have 
significantly helped them in their self-directed learning, and made them feel more focused in their preparation for their paper assessments. Feedback from consultation with core teaching staff has been that in pre-assessment tutorials the students seem 'more prepared and switched on'.

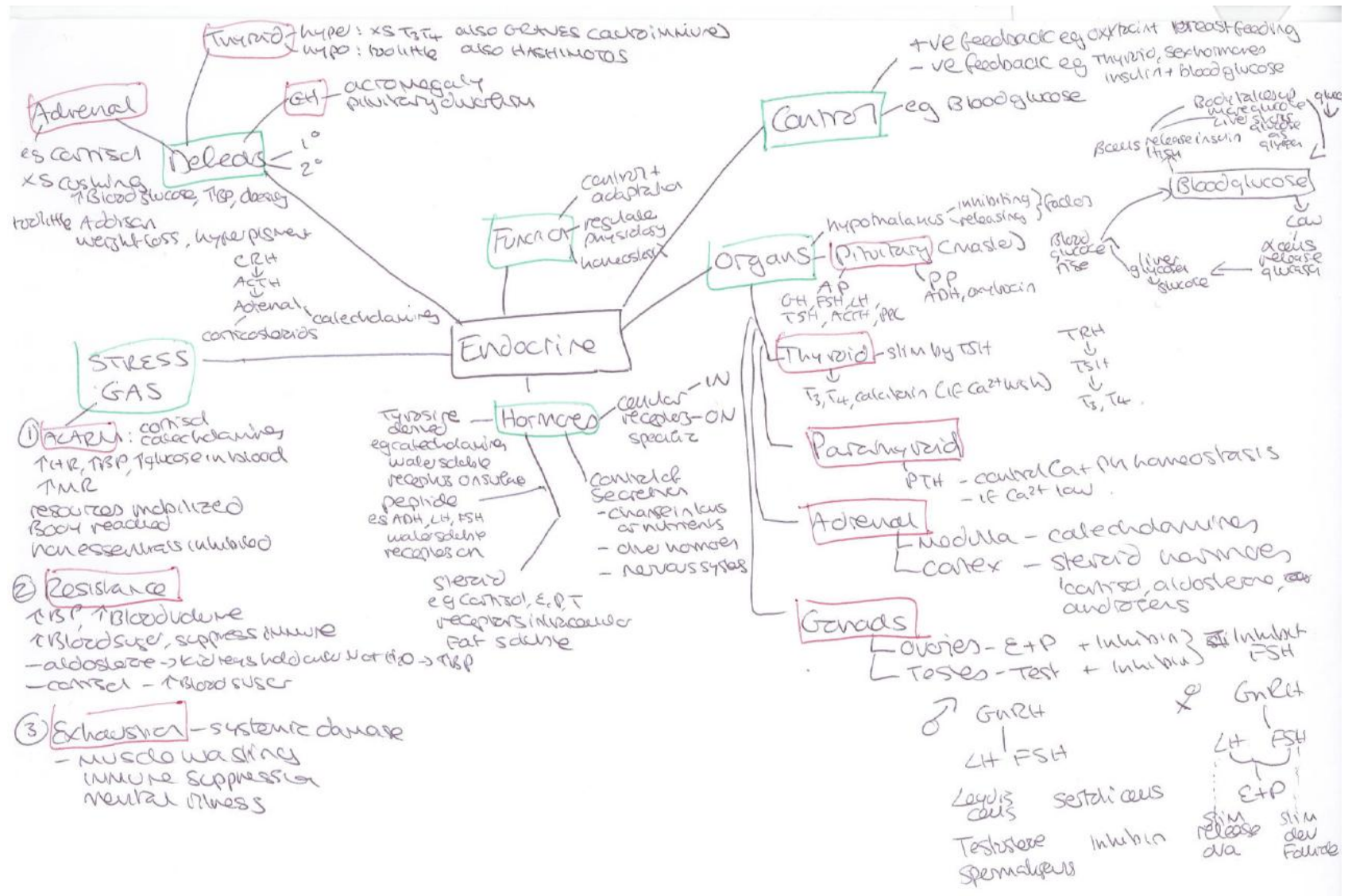

Figure 1. Visual summary generated as part of a large group teaching session

\section{Science Vocabulary Tool}

The vocabulary tool was developed as a PowerPoint presentation on continuous loop that was integrated into the student's online learning environment for the paper. It has also been made available for the students to open up as a separate entity and engage further with the tool if so desired. The tool is divided up into alphabetic categories and then commonly used roots in each category are demonstrated visually alongside basic definitions of terms commonly used in the health science papers. The key is to make it clear, simple and visual to aid memory by association of the words with the visual representations. The roots are grouped alphabetically on a title slide (see Figure 2 for example) for ease of navigation and hyperlinked so students can navigate the tool easily, if they so wish. For each of the initial 70 core root derivatives there is a separate slide with a pictorial representative and word descriptor of the root meaning as well as several applications and brief definitions of the root in the context of the first year health sciences papers to the B HIth Sci students (Figure 3). 'Additionally' there is also the facility for the students to open up the tool as a separate entity in PowerPoint and engage further with the tool if so desired. The tool is seen as an evolving application, and an 'add word' function is also present so students can enter suggestions for inclusion of words that they find difficult to be incorporated in the tool. The Stage 1 roll-out of the tool was for the 214.102 Applied Sciences for Health Professionals paper in Semester 2 July 2013, with more than 300 students enrolled. Stage 2 roll-out after student feedback was summer school November 2013 and Semester 12014 for students taking the 214.101 Normal Body Function paper, again with more than 300 students enrolled. Initial usage data shows for the Stage 1 roll out 146 students accessed the vocabulary tool, there were 347 hits on the tool altogether from the 146 students ranging from 1-12 hits per student, this is on average 2.4 times per student suggesting that when students accessed the tool they found it useful and chose to revisit it again on a subsequent occasion. 


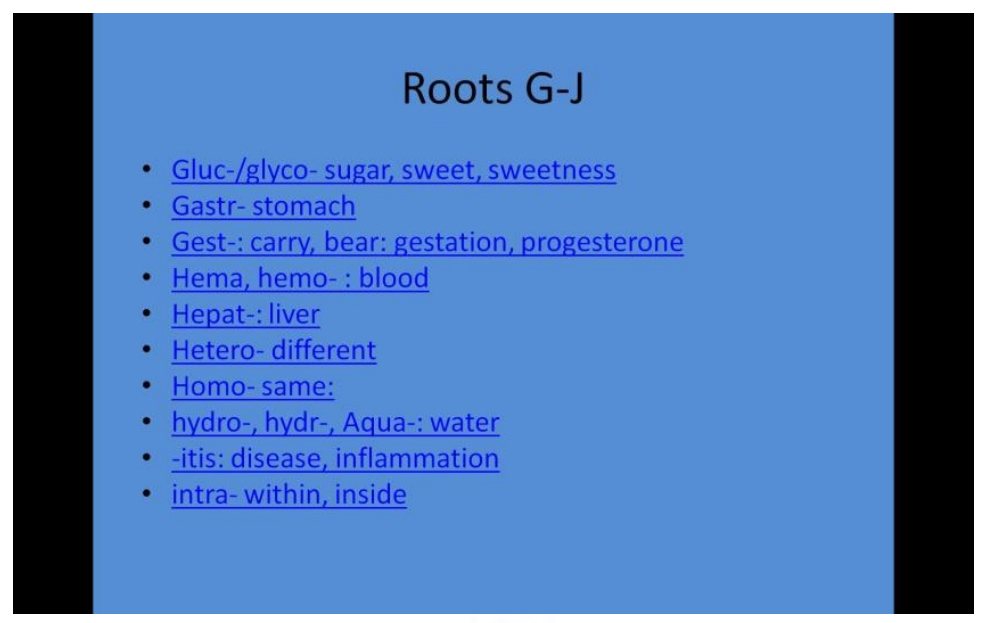

Figure 2. Screen shot of root derivative top slide G-J

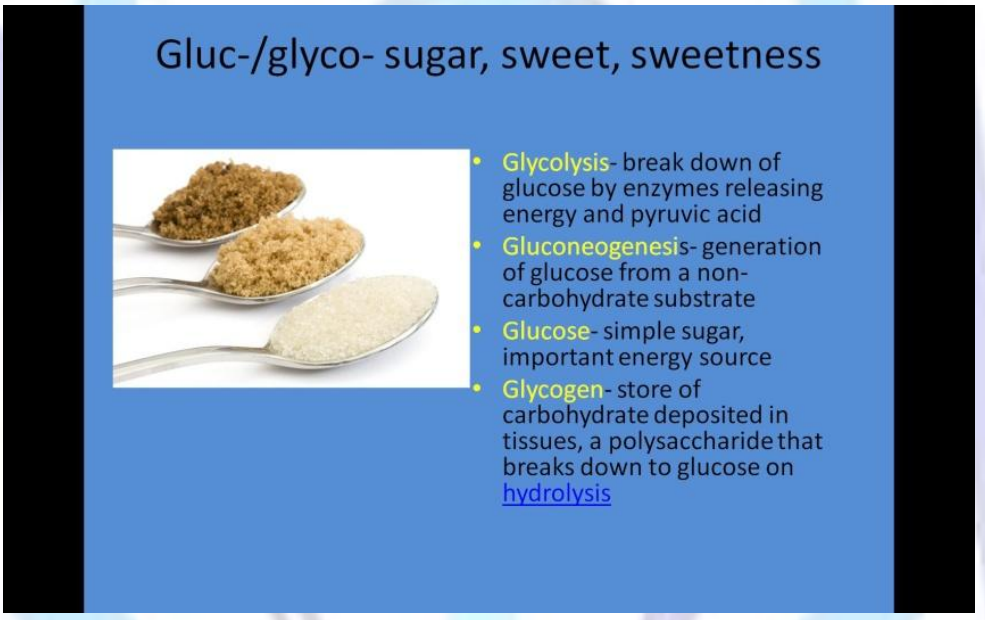

Figure 3. Screen shot of an example of a root derivative with pictorial representation and Health Science contextual description

\section{DISCUSSION}

Cognitivist thought on learning promotes the active engagement of the student in the learning process and stresses that the students are not passive but have to create meaning from a teaching session themselves. Therefore there is an important role on the part of the teacher to help the learner create structure and association from a teaching session in order to process the information presented and give it some relevance and context in the scheme of the student's prior knowledge. This paper reports the development of two initiatives. The first being the integration of visual summaries into teaching practice to aid student learning. Initial feedback from teaching staff has been that the incorporation of visual summaries has benefited large group teaching where their development has been used as an 'in class' activity or as a revision aid. This has generally taken place as short 'time out' sessions where students brainstorm and work in pairs to come up with key concepts for a visual summary. Both staff and students have commented on the benefit of this opportunity for students to reflect and question their learning and thus enabled more active and effective learning in the large lecture setting. Also this initiative enabled lecturers to help students find links with concepts across the whole semester, as the bioscience papers tend to be broken up into systems which are often presented as individual entities. In focus groups held with students key points raised were that the visual summaries have significantly helped students in their self-directed learning, and made them feel more focused in their preparation for their paper assessments. Feedback from consultation with core teaching staff has been that in pre-assessment tutorials the students seem 'more prepared and switched on'. Creating a visual summary only needs pen and paper, so is something students could easily do for themselves at no additional expense. The general process in creating a visual summary should be taught as a learning tool, it is often easy for educators to assume certain learning skills based on our own experience. What we have learnt here is that often we should remember our role as learning guides and help equip our students with these learning tools.

The second initiative described here is the development of a simple vocabulary tool designed to enhance student learning through the improvement in comprehension of basic health science words. The tool has been integrated in the Moodle online learning environment as a 3 minute video and as a function that can be downloaded and interacted with in slower 
time. This tool is now available to all first year health science students taking the 214.102 Applied Sciences for Health Professionals paper and will evolve in response to student input and feedback for inclusion of further words. Knowledge, described by Popper is 'not a product but a process', as a teacher it is important to enable students to develop confidence in their problem solving ability and to help them 'economise in the use of the mind' that is helping them to develop skills which search for 'relevance and structure' within text and to encourage reflective learning (17). Both initiatives here have been introduced for this reason, to help students develop their confidence as learners and reduce the apprehension faced by new students from the density of information.

Maslow spent a lot of his time investigating motivation, believing that learning is satisfying inner drives and needs and that motivation comes from within. He believed that in the learning situation motivation may not be possible to achieve unless certain other basic needs such as esteem, social needs, physiological needs etc. have been satisfied. Maslow's major contribution was his theory of self-actualisation- allowing a person to grow to their 'optimal stature' (18). His beliefs were centred around 'intrinsic learning' that focuses on the development of 'wisdom' and 'life skills'. What we report here focuses on the importance of the role of the lecturer as a helper and guide, that is to try to understand the students motivation, accepting the student as they are and focusing on the student's 'growth'. Maslow believed that predetermined or uniform learning outcomes are not achievable in an adult learning programme because each learner takes away what they need i.e. learning is unique. An important point to take is the importance of the student developing their own activity which leads to their understanding hence our role as educators is to guide them on this journey and provide tools for helping them actualise their goals. Sometimes it is important to step back in our age of increasingly technological competency and draw upon a more 'back to basics' approach with our roles as guides and the importance of practical examples of learning skills not being underestimated in terms of usefulness to a students learning development.

\section{ACKNOWLEDGMENTS}

Our thanks to our students, it is from them we learn to be better teachers.

\section{REFERENCES}

[1] Biggs, Teaching for quality Learning at University; second edition 2003 published by SRHE and Open University Press

[2] Knowles M 1996 Andragogy: an emerging technology for adult learning in R Edwards, A. Hanson and P Raggatt 1996 eds Boundaries of Adult learning, London : Routeldge/Open University

[3] Rogers: Teaching Adults; 2002 Third edition Open University Press

[4] DfEE 1998 The learning age: a renaissance for a New Britain, London: DfEE Cm 3790

[5] Manzo, A, Manzo U, and Thomas M,. 2006 Rationale for systematic vocabulary development: antidote for state mandates. Journal of adolescent and adult literacy 48(7) 610-619

[6] Clarke, I, Flaherty, T \& Yankey M (2006) Teaching the visual learner: The use of Visual summaries in Marketing Education. Journal of Marketing Education, vol.28. No.3 218-226

[7] Wellington $\mathrm{J}$ and Osbourne $\mathrm{J} 2001$ Language and literacy in science education. Philadelphia, PA: Open University press

[8] Pressley M 2002 Comprehension instruction: what makes sense now, what might make sense soon. Reading online, 5 (2)

[9] Nagy W and Anderson R How many words are there in printed school English? Reading research quarterly, 19, $304-$ 330

[10] Stahl S 1999 Vocabulary development. Cambridge, MA, Brookline books

[11] Kieffer M and Lesaux N 2007 . Breaking down words to build meaning: morphology, vocabulary, and reading comprehension in the urban classroom. The reading teacher 61(2) pp134-144

[12] Mountain, L 2005 ROOTing out meaning: more morphemic analysis for primary pupils The reading teacher, 58 (8), 742-749

[13] Kail,S 2008 Vocabulary Instruction goes old school. English Journal, Vol. 97, No. 4

[14] Harmon J, Wood, K, Hedrick W, Vintinner J and Willeford T 2009 Promoting vocabulary learning with the interactive word wall. Middle school journal, 40 (3), 58-63

[15] Hennings D 2000 Contextually relevant word study: Adolescent vocabulary development across the curriculum. Journal of adolescent and adult literacy, 44(3) 268-279

[16] Thunders M, Jing Y, Page R. (2013). The language of science: an online animated tool for learning the vocabulary used in the health sciences In M. Gosper, J. Hedberg, H. Carter (Eds.) Electric Dreams. Proceedings ascilite Sydney 2013. 
[17] Skinner in Theories of learning by B Hergenhan Prentice-Hall 1997

[18] Jarvis in The theory and practice of teaching edited by Kogan Page 2002; Chapter 4 : Ethics and education by Bob Brownhill and Peter Jarvis

\section{'Author's' biography with Photo}

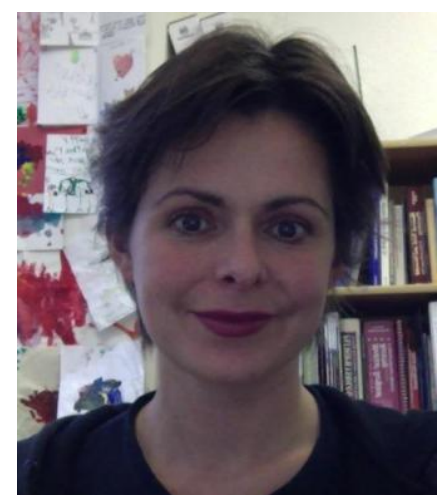

Dr Thunders completed her BSc and PhD in human genetics at University College London in 2001, as a lecturer she has worked in the tertiary education sector in the UK (University of Westminster, Institute of Child Health, and Peninsula Medical School) and now resides in New Zealand (Massey University) as a Health Sciences lecturer. She has co-authored a text book, entitled Molecular Therapeutics; $21^{\text {st }}$ Century Medicine which looked at novel emerging molecular techniques for treating disease and has a wealth of experience designing distance and online teaching materials for a range of students and health care professionals. She is a passionate teacher and communicator.

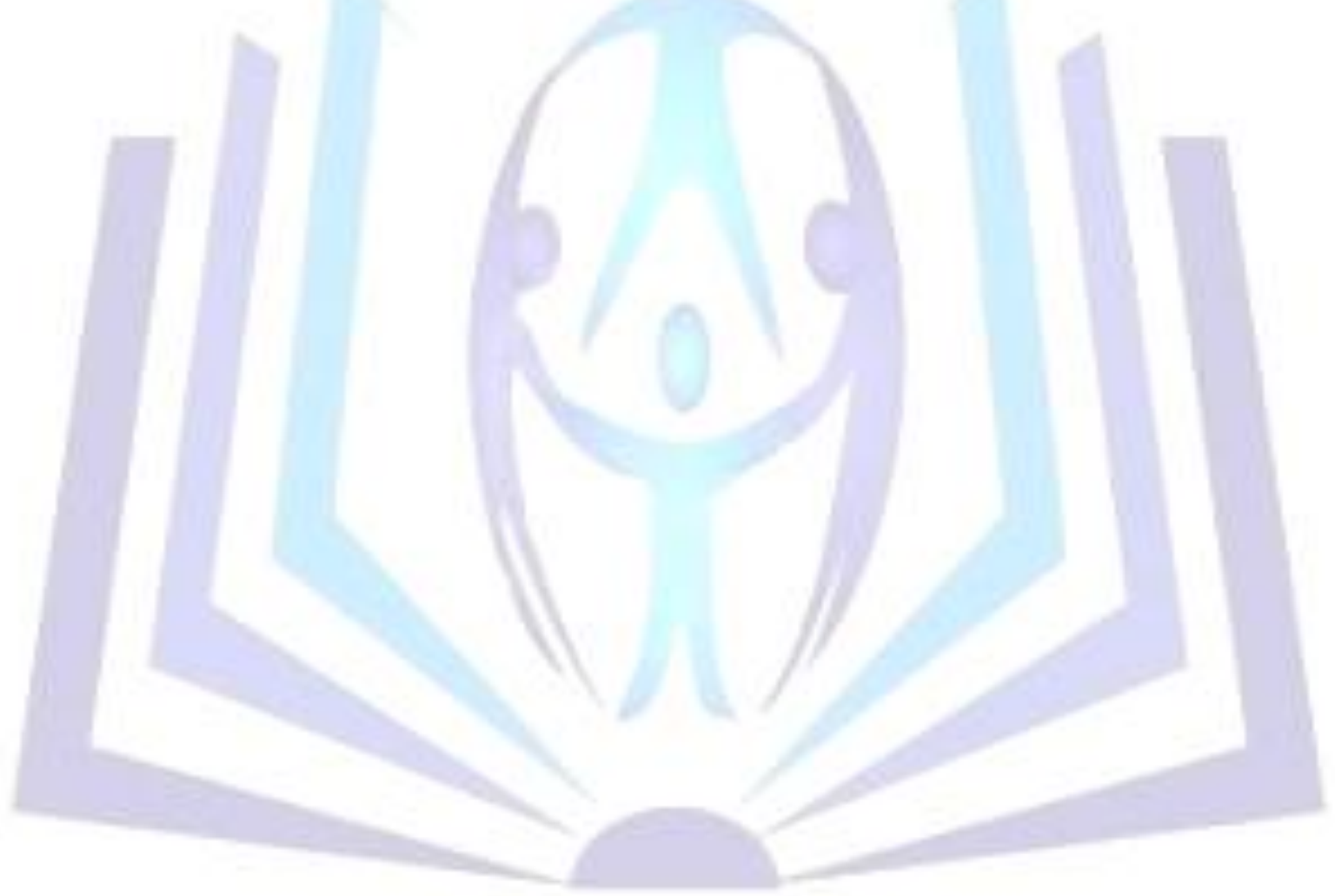

